\title{
HSE 方法在海外路桥建设项目安全管理中的应用研究
}

\author{
Research on the Application of HSE Method in the Safety Management of the \\ Overseas Road and Bridge Construction Project \\ 张建春
}

Jianchun Zhang

中交一公局集团海外分公司

中国・北京 100024

CCCC First Highway Engineering Company Ltd., Beijing, 100024, China
【摘要】文章在深入研究 HSE 管理理念的基础之上, 结合海外路桥建设项目的特殊性, 提 出了 HSE 管理的措施和方法, 经施工验证具有良好的效果, 可以为同类项目的组织与管理 提供借鉴。

【Abstract】Based on the in-depth study of HSE management concept and the particularity of overseas road and bridge construction projects, this paper puts forward the measures and methods of HSE management, which have good results after construction verification, and can provide reference for the organization and managementof similar projects.

【关键词】施工管理方法; 海外路桥建设项目; 安全管理

【Keywords \construction management method; overseas road and bridge construction project; safety management

【DOI \10.36012/etr.v2i1.1006

\section{1 引言}

随着中国在世界经济中所占比重越来越大，中方在海外 承揽的建设工程项目逐渐增多, 其中又以道路和桥梁（统称 “路桥” )等基础性建设项目所占比重最大。海外建设项目相比 中国项目, 施工安全相较于质量、工期、成本, 会受到更多不可 控因素的影响。因此, 必须施行更加科学、规范、严格的管理, 通过提高管理水平来实现管理效益的跃升, 最终带动项目建 设安全管理目标的实现。

HSE (Health-Safety-Environment, 即健康、安全和环境)管 理是目前最有效、最系统的安全生产管理办法,起源于石油天 然气勘探开发行业,近年来在建筑、路桥等工程建设项目中获 得了广泛的运用。文章探索了 HSE 管理方法在其中的应用, 为国际同类工程项目施工管理提供理论和经验的参考。

\section{HSE 管理方法概述}

HSE 管理方法是健康、安全和环境三位一体的管理体 系。其中, 健康是指人的身体和心理状态, 安全是指劳动生产 过程中的劳动条件和各项保障措施, 环境是指影响生产和各 类参与者状态的各种自然因素及其相互之间的关系 ${ }^{[1]}$ 。安全
是健康和环境的基础, 没有安全另外两项很难保证。因此, HSE 方法更多地关注安全管理。

利用 HSE 开展安全管理, 离不开 PDCA(Plan-Do-CheckAct, 即计划-执行-检查-处理) 的管理思想。具体来说, 就是 要在项目建设方、参建各方甚至业主方相关领导组成的 “小 组” 领导下, 在工程项目建设之前进行安全风险因素识别, 然 后针对潜在的安全风险源进行风险大小的评估, 最后针对每 感因素采取预防措施, 并通过对安全风险管理过程的监督而 提出改进意见。

建筑施工企业实施 HSE 安全管理, 通过事前辨识安全风 险源、评判安全风险等级, 事中采取有效的控制措施和应急预 案来把安全风险降到最低,以防止安全事故的发生。

\section{3 影响海外路桥建设项目的安全风险因素}

中方在海外承揽的路桥建设工程项目, 一般采用中方建 筑标准进行施工, 组织管理方为中方或中外合作, 但参建各方 多为外方施工队伍, 在建设工程管理过程中除了要与不同国 家民族的人打交道外, 还要考虑到异国特殊的政治文化氛围 和自然地质条件。这些都会给海外路桥项目建设施工带来安全 风险, 其中影响比较大的主要因素可以归纳为以下几个方面。 


\section{1 不同的政治文化风俗习惯带来的安全风险}

中国在海外承揽的建设工程项目, 主要集中在第三世界 国家, 这些国家很多是原西方殖民地, 受西方国家政体影响较 为深远, 法律体系和政治规则与中国有很大不同。同时, 外方 参建人员多有宗教信仰, 加上语言沟通不畅、工作习惯和思维 方式的不同,往往会造成信息传递、沟通理解的困难,处理不 好会产生不必要的麻烦。另外,很多国际业主方不注重施工合 同的制定,造成项目管理不够规范,假如出现安全问题就会最 终导致责任界定不清、管理过程中的推诿扯皮。不同的政治文 化风俗习惯带来了比中国更加复杂的安全风险。

\section{2 特殊的自然地质环境和施工技术带来的安 全风险}

很多海外国家, 尤其是非洲国家, 地形地质地貌比较特 殊。比如, 有一种黑棉土地质, 广泛分布在非洲东部, 表面呈黑 色且具有较强吸水膨胀性, 经常因为雨水的缘故导致路基及 铺完沥青的路面上出现开裂、波浪等病害。同时,非洲气候复 杂多变、雨季雨量充沛, 容易造成洪水泛滥。这些特殊的自然 地质环境必然对勘探手段和施工方法提出更高的要求, 必要 时还需要采用一些特殊的施工机械, 这些都会直接或间接影 响到施工安全。

\section{3 非专业化的当地施工队伍带来的安全风险}

海外工程的不连续性、规模小、道路等级低这些特点, 导致 海外项目专业分包队伍市场发展缓慢, 面对“一带一路”大量增 加的工程任务, 专业队伍出现严重紧缺, 处于供不应求的状态, 而且大多数队伍只能分包路基土石方、浆砌等普工多、工艺简 单的分部分项工程。分包商普遍存在无法按计划独立完成工 作任务的情况, 另外对于桥涵、路面、轧石等当地队伍没有能 力完成的专业施工, 需要引入中国分包商或组织自营, 项目生 产组织体系比较复杂, 对应的安全管理工作也变得复杂。

\section{4 海外路桥建设项目 HSE 管理方法}

安全管理方法要注重 “以人为本”, 最主要的手段在于通 过提高人员安全管理意识、落实安全管理责任和措施来确保 安全生产。具体来说, 为做好海外路桥建设项目的 HSE 施工 安全管理,需要做好以下几方面的工作。

\section{1 树立 HSE 安全管理理念}

HSE 管理连接健康、安全、环保三大核心理念, 体现了以 人为本的根本思想, 和工程项目的每一个参与个体都有关系 ${ }^{[2]}$ 。 要做好 HSE 管理, 首先要在项目内部大力宣传 HSE 管理理 念, 确保每一名员工都清楚 HSE 安全管理的目标和措施; 其 次, 要定期开展 HSE 培训, 让每一名员工明白 HSE 管理的重
要性和不同工程节点不同的 HSE 管理措施, 不断强化按照 HSE 开展管理、保障安全的意识; 最后, 要加强管理者责任心 的培养。只有管理者制定完善的计划并督促落实、积极检查, 才能够确保 HSE 安全管理理念落到实处。

\section{2 建立 HSE 安全管理体系}

基于海外路桥建设项目构建的 HSE 安全管理体系, 第 一, 要明确责任, 按照“党政同责、一岗双责、失职追责”的原则 明确参建各单位、各部门的岗位职责, 并具体细化到个人; 第 二, 要注重发挥好领导作用, 各级领导干部在安全管理工作中 负有主要责任, 安全管理措施也要借助领导力量得到贯彻落 实; 第三, 要将安全管理目标写进纲领性程序文件中, 通过有 效的形式传达给所有项目的参与人员; 第四, 要编制好 HSE 安全管理的相关文件, 如组织机构文件、管理目标和方针、健 康安全与环保管理计划、教育培训计划、危险品管理使用计 划、风向评估方案、特殊情况处理意见和应急方案、现场管理 方案等, 在施工过程中严格依据这些程序文件开展管理活动, 做好记录, 并定期进行讲评; 第五, 要组织好各种会议,包括安 全生产会议、事故情况分析会议等,通过会议明确安全管理的 相关事项并做好研究与传达。

\section{3 做好培训教育和考核}

各类安全事故都是可以预防的, 因此, 需要建立相关的应 急预案, 并按照预案的内容开展教育培训, 确保每一名参加施 工的个人都了解预案的内容并会按照步骤进行操作。同时, 对 于安全管理教育培训开展情况以及措施落实情况要进行绩效 考核,通过公平合理的手段并辅以经济奖惩方式,以实现各级 管理部门的安全监督与指导职能。

\section{5 结论}

HSE 安全管理要求在保障健康和环境的基础上,全面考 虑施工过程中的每一项因素, 制定切实可行的安全管理目标 和方案，在施工组织实施中细化为具体的措施来保证各项管 控工作落地。通过实施 HSE 管理, 中方几个海外高速公路和 桥梁建设项目在预定工期内高质量完成, 取得了施工质量、工 期、人员安全、环保、预期的施工利润和政治影响, 各方普遍比 较认可, 进一步证明了 HSE 安全管理对于促进海外类似项目 的开展具有一定的指导意义。

\section{参考文献}

[1]周伟.浅析建筑施工企业国际工程项目 HSE 管理[J].中小企业 管理与科技(上旬刊),2017(7):19-20.

[2]赵哲.建筑施工项目 HSE 管理体系建设探析 [J].全面腐蚀控 制,2019(6):54-56 